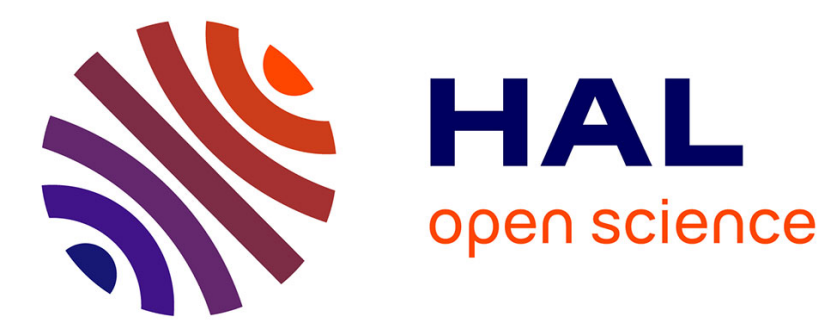

\title{
Hedonic prices for cars: an application to the Spanish car market, 1981-2005
}

Anna Matas, Josep-Lluis Raymond

\section{To cite this version:}

Anna Matas, Josep-Lluis Raymond. Hedonic prices for cars: an application to the Spanish car market, 1981-2005. Applied Economics, 2009, 41 (22), pp.2887-2904. 10.1080/00036840701720945 . hal00582130

\section{HAL Id: hal-00582130 \\ https://hal.science/hal-00582130}

Submitted on 1 Apr 2011

HAL is a multi-disciplinary open access archive for the deposit and dissemination of scientific research documents, whether they are published or not. The documents may come from teaching and research institutions in France or abroad, or from public or private research centers.
L'archive ouverte pluridisciplinaire HAL, est destinée au dépôt et à la diffusion de documents scientifiques de niveau recherche, publiés ou non, émanant des établissements d'enseignement et de recherche français ou étrangers, des laboratoires publics ou privés. 


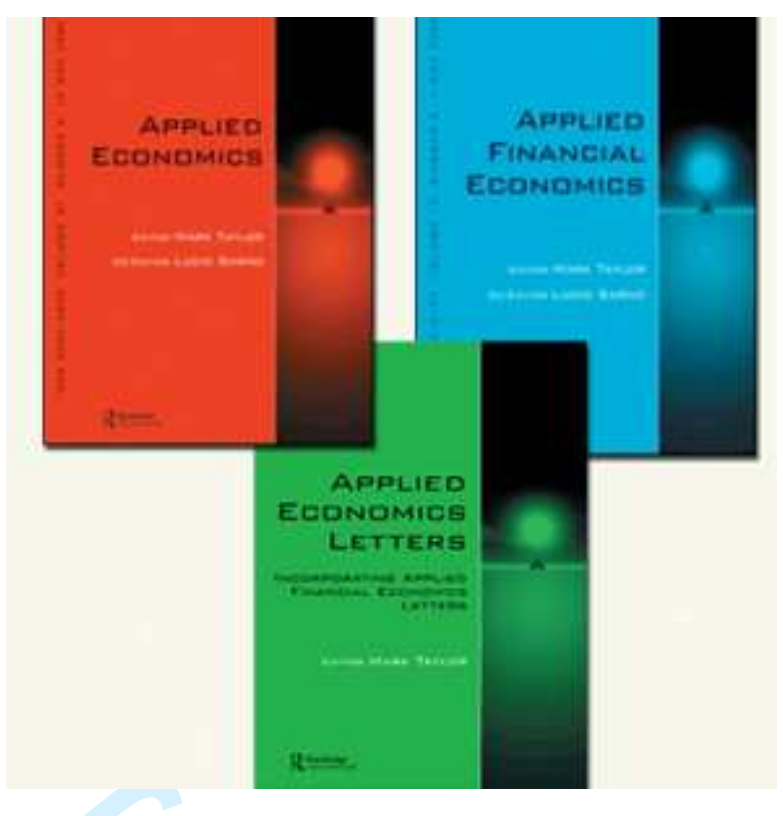

\section{Hedonic prices for cars: an application to the Spanish car market, 1981-2005}

\begin{tabular}{|r|l|}
\hline Journal: & Applied Economics \\
\hline Manuscript ID: & APE-06-0310.R1 \\
\hline Journal Selection: & Applied Economics \\
\hline $\begin{array}{r}\text { Date Submitted by the } \\
\text { Author: }\end{array}$ & 06-Jul-2007 \\
\hline Complete List of Authors: & $\begin{array}{l}\text { Matas, Anna; Universitat Autonoma Barcelona, Economia Aplicada } \\
\text { Raymond, Josep-LLuis; Universitat Autonoma Barcelona, Economia }\end{array}$ \\
\hline JEL Code: & $\begin{array}{l}\text { C51 - Model Construction and Estimation < C5 - Econometric } \\
\text { Modeling < C - Mathematical and Quantitative Methods, L62 - } \\
\text { Automobiles|Other Transportation Equipment < L6 - Industry } \\
\text { Studies: Manufacturing < L - Industrial Organization }\end{array}$ \\
\hline Keywords: & Hedonic prices, Car prices \\
\hline
\end{tabular}

\section{scholarONE" \\ Manuscript Central}


Hedonic prices for cars: an application to the Spanish car market, 1981-2005.

\author{
Anna Matas* \\ Departament d'Economia Aplicada, Universitat Autònoma de Barcelona, \\ 08193 Bellaterra, Barcelona, Spain \\ anna.matas@uab.es \\ Josep-LLuis Raymond \\ Departament d'Economia i Història Econòmica, Universitat Autònoma de Barcelona, \\ 08193 Bellaterra, Barcelona, Spain \\ josep.raymond@uab.es \\ *Corresponding author. Tel.: +34.93.581.1578; Fax: +34.93.581.2292
}

\begin{abstract}
In this paper we provide a comparison of different formulations for hedonic regression analysis in order to construct a quality-adjusted price index for the Spanish car market over the period 1981-2005. Specifically, we address the issue of instability of coefficients over time, and propose two alternative estimation procedures based, firstly, on a moving sample of observations and, secondly, on a moving average of estimated coefficients in single period equations. The statistical tests applied support the proposed methodologies. On empirical grounds two conclusions can be emphasised. Firstly, our study concludes that, taking quality changes into account, car prices in Spain deflated by CPI declined by $40 \%$ between 1981 and 2005 . This result is robust to the alternative estimation procedures employed in the study. Secondly, an analysis of sigmaconvergence shows that for quality-adjusted prices a clear trend in $\sigma$-convergence emerges between 1986 and 1992, whereas such a trend does not exists for observed prices. This result has to be related to Spain's integration into the European Community.
\end{abstract}




\section{Introduction}

Quality improvements over time for some durable goods pose the long-discussed question of how to construct price indexes taking quality changes into account. As is well-recognised, the hedonic approach offers an adequate methodology to adjust prices for quality changes.

In this paper we address the issue of instability of coefficients of the hedonic equations over time, and present two alternative methodologies to deal with this problem. As is known, the hypothesis of parameter stability over time assumed by the traditional pooled regression approach is often rejected by the data. On the other hand, single period regression equations tend to estimate erratic coefficients, due, at least partly, to econometric problems. Our proposal builds on an intermediate solution between the two aforementioned approaches. We propose firstly to estimate the hedonic equation using a moving sample, and secondly, to compute the implicit price for the characteristics from a weighted moving average of the coefficients estimated in the single period regressions. Moreover, statistical tests are provided to test the simplifying assumptions. The proposed methodologies are also compared with the frequently used adjacent year approach. Besides, the study offers a comparison of quality-adjusted price indexes constructed using each of the alternative methodologies.

We have applied the proposed methodology to the Spanish car market over the period 1981-2005. The choice of the car market is justified by the large number of quality improvements in the performance and characteristics of cars that has taken place as a result of technological changes. Quality improvements can be observed in different 
areas, such as comfort, safety, performance, reliability and fuel efficiency. In fact, the seminal papers on hedonic methodology by Court in 1939 and Griliches in 1961 are both applied to the car market.

On empirical grounds, the paper presents a decomposition of the variation in observed automobile price into the variation due to changes in the characteristics and a pure or quality-constant price effect. Moreover, the approach makes it possible to compute an index for the various quality dimensions. Finally, the paper shows a process of sigmaconvergence in quality-adjusted prices related to Spain's integration into the European Community (EC).

2. The hedonic methodology

2.1. Background

The first empirical research relating price and quality is attributed to the work of Waugh, who in 1928 estimated a price function on vegetables (Berndt, 1991). In 1939 Court estimated a multiple regression equation, which he named hedonic method, which related car prices to the relevant car characteristics, with the final objective of constructing a quality-adjusted price index for the automobile market in the US. However, it was not until Griliches's work in 1961, also applied to the car market, that the hedonic approach became widespread. Nowadays it is used by some statistical agencies to compute price indexes adjusted by quality, and there has been a renewed interest from empirical and theoretical research. In particular, this method is applied to the computer, automobile and housing markets. A recent and up to date review can be found in Triplett (2004). For the car market, see the studies by Otha and Griliches 
(1986), Bajic (1993), Arguea et al. (1994), Raff and Trajtenberg (1995), Murray and Sarantis (1999), Izquierdo et al. (2001), Reis and Santos Silva (2002), van Dalen and Bode (2004) and Requena-Silvente and Walker (2006).

The underlying hypothesis of the hedonic analysis is that goods can be viewed as a bundle of attributes or characteristics, and the demand for a good is really a demand for the attributes it contains. According to this hypothesis, the price of a good can be expressed as a function of its characteristics, and the relationship between price and characteristics is called the hedonic function. The estimation of a hedonic price equation makes it possible to distinguish between the variation in prices explained by a change in the characteristics and the variation that can be attributed to a pure price effect.

Initially, hedonic regressions were viewed as an ad hoc empirical instrument to construct a quality-adjusted price index. Its theoretical basis is found on the consumer theory developed among others by Houthakker (1952) and Lancaster (1966) in the characteristics space. Later, Rosen (1974) expanded the theoretical foundation ${ }^{1}$. In this study, we interpret the hedonic equation as an instrument to approximate the evolution of price indexes, taking into account the variation in product characteristics. Regression coefficients can be interpreted as implicit prices for characteristic.

\footnotetext{
${ }^{1}$ Rosen (1974) developed a theoretical framework for hedonic prices as equilibrium prices for supply and demand functions, both defined on the characteristics of products. Under this framework, the characteristic coefficients in the hedonic equation are the result of the interaction between the consumer's marginal valuation and the producer's marginal cost. As has been demonstrated by many authors, only under very restrictive assumptions is it possible to identify estimated coefficients as consumers' preferences or producers' costs. However, this problem does not affect the possibility of computing the hedonic index as an approximation to the exact hedonic index. Moreover, several publications by A. Pakes (Pakes, 2003; Pakes, 2004) have recently revived the interest in the economic rationale of hedonic prices. This author derives the hedonic framework from the industrial organization theory in the context of technological change, differentiated product markets and heterogeneous consumers. Under his approach producers' mark-ups are a function of the characteristics and costs of all goods and of the distribution of consumer attributes, and vary over time and depending on products. Under this approach, the coefficients in the hedonic equation may vary quickly over time and do not necessarily have to take the expected sign. Pakes's formulation has received great attention in hedonic literature. It has however generated some still unresolved controversies (see, for instance, Triplett, 2004, p. 159).
} 
Despite the large literature devoted to the hedonic price function, some methodological problems have yet to be solved ${ }^{2}$. One of these problems is how to deal with the instability of coefficients over time. In the following section, two possible solutions to this issue are proposed.

\subsection{Alternative proposals for estimating hedonic prices}

Given that the coefficients in the hedonic equation can be interpreted as the result of the interaction of the demand and supply curves for characteristics, a shift in any curve might cause a change in the estimated coefficient over time. Thus, in empirical implementation, the stability of the parameters over time has to be tested. The most obvious alternative consists of estimating year-by-year equations and testing equality restrictions among coefficients.

The problem with single year equations is that the estimated coefficients tend to be very erratic due to the reduced number of degrees of freedom along with a high level of multicollinearity among characteristics. In that case, it is not possible to obtain a reliable valuation of individual characteristics or any group of them over time ${ }^{3}$.

\footnotetext{
${ }^{2}$ See Diewert (2003) and Triplett (2004, chapters V and VI).

${ }^{3}$ Empirical evidence shows that the estimated coefficients in yearly equations are highly volatile. As long as these coefficients approximate implicit prices for characteristics, it seems desirable for both their magnitude and sign to behave according to the expected values. In our view, the volatility in the estimates can be largely explained by econometric problems. The main problems when estimating hedonic equations are multicollinearity and the reduced number of degrees of freedom which result in large variance of some of the estimated coefficients which in turn produce instability in their value. This view has however been recently disputed by Pakes in several provocative papers. In the context defined in footnote 2, this author argues that the coefficients in the hedonic function do not necessarily obey any of the restrictions associated with utility or costs functions (Pakes, 2004). As has been recognised (Berndt and Rappaport, 2003; Triplett, 2004, p.236-238), although some of the issues in Pakes's work are still controversial, it has made remarkable contributions to the hedonic theory. The issue we address in this paper is the econometric problems that arise when estimating yearly equations with limited sample size.
} 
The present paper proposes two alternative methodologies for improving the way the value of the characteristics is estimated. The first alternative is based on the estimation of the regression equations using a moving sample of the observations, and the second, on a weighted moving average of the estimated coefficients in the single period equations. In each case it is necessary to fix the best order for the averages. With the aim of validating the alternatives, the underlying hypothesis of equality of coefficients is tested for each specification. Additionally, the study shows how the new proposals improve the results obtained in the adjacent period approach, which is the common way to address the problem of coefficients instability.

Finally, our results corroborate the previous finding that instability of individual coefficients is not a problem for the construction of a hedonic price index. The adjusted quality price index is very similar for all alternatives approaches. This result confers robustness on the estimation of the hedonic price index. The five alternatives used in estimating the hedonic equations are set out below.

1. Time dummy variable method or pooled equation

This method assumes constant coefficients and includes time dummy variables. It has been widely used in empirical research in hedonic prices. All the observations are "pooled" into a single regression equation and the estimated coefficients are common to all periods. The estimated equation can be expressed as:

$$
p_{i t}=\alpha+\delta_{t}+\beta^{\prime} X_{i t}+\gamma^{\prime} Z_{i t}+\varepsilon_{i t} \quad t=1,2, \ldots, T
$$


Where $p_{i t}$ is the price of car model $i$ in period $t$; $X_{i t}$ is the vector of car characteristics $Z_{i t}$ is the vector of car brands $\delta_{t}$ annual dummy variables

The hypothesis of stability of coefficients over time can be tested using a conventional F test.

\section{Single period equations}

In the unconstrained approach, separate equations are specified for each time period:

$$
p_{i}=\alpha+\beta^{\prime} X_{i}+\gamma^{\prime} Z_{i}+\varepsilon_{i}
$$

\section{Adjacent year equations}

This approach combines data from two periods so that the characteristic coefficients are held constant only for two periods. A time dummy variable, $\delta$, is included for the second year. This approach is also targeted to improve the problem of instability of coefficients and, hence, we will devote special attention to the comparison of its results with those of our proposals ${ }^{4}$.

$$
p_{i t}=\alpha+\delta \cdot D+\beta^{\prime} X_{i t}+\gamma^{\prime} Z_{i t}+\varepsilon_{i t} \quad \mathrm{t}=\mathrm{t}, \mathrm{t}+1
$$

where $\mathrm{D}$ is a dummy variable that takes value 1 for observations in the second year.

The F-test is used to test the constraint on equality of coefficients.

\footnotetext{
${ }^{4}$ In this point we acknowledge the suggestion of an anonymous referee.
} 


\section{Moving sample of order $h$}

This is the first of the new alternatives suggested in this work. The estimated equation can be expressed as:

$$
p_{i h}=\alpha_{m s h}+\delta_{h}+\beta^{\prime}{ }_{m s h} X_{i h}+\gamma_{m s h}^{\prime} Z_{i h}+\varepsilon_{i h} \quad h=1,2, . . H
$$

where the sub-index $m s$ denotes that the parameter corresponds to a moving sample of $h$ periods.

The regression equation is estimated for a centered moving sample of order $\mathrm{h}$. A different vector of coefficients is estimated for each moving sample and, as in the previous case, an F-test allows us to test equality among coefficients and to establish the order of the moving sample.

5. Weighted moving average of the coefficients estimated in the single period regressions

The second new alternative put forward involves computing the implicit price for the product characteristics by constructing a weighted moving average of the coefficients estimated in the single period equations. This approach has the advantage that it makes it possible for the coefficient to take different values over time, while at the same time the erraticity found in annual estimates is smoothed out. Again, the restriction imposed on the coefficients and the order of the moving average can be tested. The basis for this procedure can be stated as follows. 
To fix ideas, let the order of the moving average be 3 . We have three estimates for $\beta_{i, j}$, where $i$ stands for a product characteristic and $j$ for a year: $\hat{\beta}_{i,-1}, \hat{\beta}_{i, 0}, \hat{\beta}_{i,+1}$. Let us assume that these are unbiased estimates. Then, the following estimator can be constructed $^{5}$ :

$\hat{\beta}_{i}=\lambda_{-1} \cdot \hat{\beta}_{i,-1}+\lambda_{0} \cdot \hat{\beta}_{i, 0}+\lambda_{+1} \cdot \hat{\beta}_{i,+1}=\lambda_{-1} \cdot \hat{\beta}_{i,-1}+\lambda_{0} \cdot \hat{\beta}_{i, 0}+\left(1-\lambda_{-1}-\lambda_{0}\right) \cdot \hat{\beta}_{i,+1}$

Generally, the estimator can be written as:

$\hat{\beta}_{i}=\lambda^{\prime} \cdot \hat{\theta}_{i}$, where $\hat{\theta}_{i}^{\prime}=\left(\hat{\beta}_{i,-1} \hat{\beta}_{i, 0} \hat{\beta}_{i,+1}\right)$

$\lambda^{\prime} \cdot l=1$, where $l$ is a unit vector.

It holds:

$$
\operatorname{var}\left(\hat{\beta}_{i}\right)=\lambda^{\prime} \cdot \operatorname{cov}\left(\hat{\theta}_{i}\right) \cdot \lambda
$$

By using the Lagrange multiplier method, the expression to minimise is:

$$
\begin{aligned}
& \Phi=\lambda^{\prime} \cdot \operatorname{cov}\left(\hat{\theta}_{i}\right) \cdot \lambda+\mu \cdot\left(1-\lambda^{\prime} \cdot l\right) \\
& \frac{\partial \Phi}{\partial \lambda}=2 \cdot \operatorname{cov}\left(\hat{\theta}_{i}\right) \cdot \lambda-\mu \cdot l=0 \\
& \lambda=\frac{1}{2} \cdot \operatorname{cov}\left(\hat{\theta}_{i}\right)^{-1} \cdot l \cdot \mu
\end{aligned}
$$

Multiplying by $l^{\prime}$ :

$$
l^{\prime} \cdot \lambda=1=\frac{1}{2} \cdot l^{\prime} \cdot \operatorname{cov}\left(\hat{\theta}_{i}\right)^{-1} \cdot l \cdot \mu \Rightarrow \mu=2 \cdot\left[l^{\prime} \cdot \operatorname{cov}\left(\hat{\theta}_{i}\right)^{-1} \cdot l\right]^{-1}
$$

We have:

$$
\lambda=\frac{1}{2} \cdot \operatorname{cov}\left(\hat{\theta}_{i}\right)^{-1} \cdot l \cdot \mu=\operatorname{cov}\left(\hat{\theta}_{i}\right)^{-1} \cdot l \cdot\left[l^{\prime} \cdot \operatorname{cov}\left(\hat{\theta}_{i}\right)^{-1} \cdot l\right]^{-1}=\frac{\operatorname{cov}\left(\hat{\theta}_{i}\right)^{-1} \cdot l}{\left[l^{\prime} \cdot \operatorname{cov}\left(\hat{\theta}_{i}\right)^{-1} \cdot l\right]^{-1}}
$$

Hence, the estimator of $\lambda$ that minimises the variance of $\hat{\beta}$ is:

\footnotetext{
${ }^{5}$ Granger and Newbold (1986) made a similar proposal for combining individual forecasts derived from separate models.
} 


$$
\lambda=\frac{\left[\operatorname{cov}\left(\hat{\theta}_{i}\right)\right]^{-1} \cdot l}{l^{\prime} \cdot\left[\operatorname{cov}\left(\hat{\theta}_{i}^{\prime}\right)\right]^{-1} \cdot l}
$$

If $\operatorname{cov}\left(\hat{\theta}_{i}\right)$ is a diagonal matrix, as can be expected in our case given that we run separate estimates, the weighting for $\operatorname{cov}\left(\hat{\theta}_{i}\right)$ will be:

$$
\lambda_{i}=\frac{\frac{1}{\operatorname{var}\left(\hat{\beta}_{i, j}\right)}}{\sum_{j} \frac{1}{\operatorname{var}\left(\hat{\beta}_{i, j}\right)}}
$$

Finally, we propose a procedure to determine the number of periods to be included in the moving average. Let us again assume that we have a 3-moving average. To guarantee that the estimated average has sense, we need the following assumption for the underlying population:

$\beta_{i,-1}=\beta_{i, 0}=\beta_{i,+1}=\beta_{i}$

If $\hat{\beta}_{i,-1}$ is the estimated price for characteristic $i$ using the sample for year $-1, \hat{\beta}_{i, 0}$ is the estimated price for characteristic $i$ using the sample for year 0 , and $\hat{\beta}_{i,+1}$ is the estimated price for characteristic $i$ using the sample for year +1 , the following hypotheses must be satisfied:

$$
\begin{aligned}
& \hat{\beta}_{i,-1} \rightarrow N\left(\beta_{i}, \sigma_{-1}^{2}\right) \\
& \hat{\beta}_{i, 0} \rightarrow N\left(\beta_{i}, \sigma_{0}^{2}\right) \\
& \hat{\beta}_{i,+1} \rightarrow N\left(\beta_{i}, \sigma_{+1}^{2}\right)
\end{aligned}
$$

Assuming temporal independence in $\hat{\beta}_{i}$, under the null hypothesis it must be verified that: 


$$
\left(\frac{\hat{\beta}_{i,-1}-\beta_{i}}{\sigma_{-1}}\right)^{2}+\left(\frac{\hat{\beta}_{i, 0}-\beta_{i}}{\sigma_{0}}\right)^{2}+\left(\frac{\hat{\beta}_{i,+1}-\beta_{i}}{\sigma_{+1}}\right)^{2} \rightarrow \chi_{3}^{2}
$$

This distribution is still asymptotically satisfied when the population $\sigma$ is substituted by its estimates. The proposed criterion would be similar for testing higher order moving averages.

Accordingly, the order of the moving average can be tested for each characteristic. The higher the selected order of the moving average, the higher will be the smoothing imposed on the parameters, but at the same time the higher the number of $\beta_{t}$ lost (a 3moving average implies losing the $\beta$ for the first and last year in the sample, whereas a 5-moving average implies losing two $\beta$ at the beginning and two $\beta$ at the end), and the lower the adjustment capacity of the underlying price model.

\section{The data}

The data set for our study covers a 24-year period from 1981 to 2005 . Over this period we collected data for car models with higher sales figures in Spain, coming to roughly $90 \%$ of total registrations. The total number of observations is 1970 , with an average of 82 models per year, although the number of models increases for more recent years ${ }^{6}$. In our opinion, the sample gathered is a representative sample of market trends.

\footnotetext{
${ }^{6}$ The information on sales volumes was provided by the Instituto de Estudios de Automocion (Spanish motor vehicle manufacturers' association). Unfortunately, no data was available for the different model versions. Our choice was to select a middle-range model.
} 
The prices and characteristics of the car models were obtained from specialist magazines. The price used thus corresponds to list prices, as is often the case in hedonic analysis. In addition, car prices include VAT and special car tax. Table A.1. in the appendix offers descriptive statistics for the dependent variable.

A relevant issue in hedonic analysis is the selection of the explanatory variables in the model. These variables should reflect the set of characteristics that consumers look for when choosing a new car. In this study, the selection of the variables to be included as regressors was based on the results reported in the literature ${ }^{7}$, taking into account the limitation of our data source. We expect that the characteristics used are a reasonable approximation to the consumer's price determinants. The variables are grouped into six categories and summarised in Table 1.

Dummy variables for car manufacturers were included in order to account for unobservable attributes that are related to characteristics like reliability or other unobserved attributes. Finally, annual dummy variables on imported cars entered the equation to capture the effect of tariffs. It should also be mentioned that we tried a number of other explanatory variables in preliminary analyses that did not prove to be statistically significant ${ }^{8}$.

\section{Estimation issues}

\footnotetext{
${ }^{7}$ We draw heavily on Raff and Trajtenberg (1995).

${ }^{8}$ For instance, number of gears, maximum speed, number of airbags and central locking.
} 
A second issue to be considered is whether the hedonic regression should be weighted or unweighted $^{12}$. Our preferred option has been not to weight. In fact, as Deaton (1997) remarks, under the standard assumptions of the linear regression model weighting leads

\footnotetext{
${ }^{9}$ Rosen (1974) established that the hedonic functional form is an empirical issue. Subsequent studies showed that only under very restrictive assumptions is it possible to restrict the functional form.

${ }^{10}$ It should be noted that the same result was reached by the single year equations approach. Nevertheless, it would be too cumbersome to present all the estimations year by year.

${ }^{11}$ The semi-log functional form has been widely used with automobile data; see, for instance, Bajic (1993), Murray and Sarantis (1999), van Dalen and Bode (2004) and Requena-Silvente and Walker (2006).

${ }^{12}$ A clear distinction should be made between weighting the hedonic regression and weighting the hedonic price index (see, Triplett 2004, pp.189-193).
} 
to a loss of efficiency. Even if those assumptions are not satisfied, weighting will not generally be the appropriate solution ${ }^{13}$.

Once the functional form had been selected, we proceeded to estimate the hedonic equation according to the five alternatives set out in section 2. All the equations have been estimated in current prices. This decision does not affect the estimated coefficient for the characteristics, it only affects the coefficient of the time dummy variables.

First, the estimation results for the pooled regression model, presented in Table A.2 in the appendix, show a good fit. In addition, the estimated coefficients take the expected sign and are statistically significant. Since some heteroskedasticity was observed, the variance-covariance matrix was computed using the White procedure. However, the standard errors were very similar in both formulations; i.e., under the standard approach or using White formulation. It is interesting to test whether disturbance heteroskedasticity is present over time. In order to test this possibility we followed the procedure suggested by Berndt and Rappaport (2003). Thus, we regressed the squared residuals on a constant and a set of annual dummy variables, and computed the F-test

\footnotetext{
${ }^{13} \mathrm{~A}$ frequently discussed issue in the literature is whether in order to estimate the hedonic price equations the variables must be weighted or not. In fact, under the usual regression model hypothesis, weighting the observations by the market shares of car models has not a conceptual justification. As it is well known, in this case weighting must lead to a loss of efficiency meanwhile not weighting must lead to a BLU estimation. Also, under these hypotheses, both weighted least squares and unweighted least squares must be consistent. So, if the model specification satisfies the standard hypothesis, it could be expected that weighted and unweighted least squares will lead to similar values for the estimated coefficients. Nonetheless, for the exposed reasons, the not weighted least squares is the preferred alternative. In our case, using a sample for the period 1987-2004 for which data on sales by car model are available, the estimated parameters in the weighted and not weighted alternatives are rather similar. Computing a 95\% confidence interval for the valuation of the characteristics that results from the two options the two intervals always overlap, and taking as a reference the unweighted estimates, the percentage of overlapping is $47 \%$ for the variable displacement, $74 \%$ for H.P/weight, $92 \%$ for size, $84 \%$ for fuel consumption, $84 \%$ for diesel, $54 \%$ for minivan, $67 \%$ for number of doors, $94 \%$ for air conditioned, $87 \%$ for climate control, $88 \%$ for ABS, $63 \%$ for assisted steering, $94 \%$ for electric windows and $100 \%$ for automatic gear.
} 
for joint equality of the residual variances across all years. The null hypothesis of homoskedasticity over time was not rejected $(\mathrm{F}=1.299$, $\mathrm{p}$-value $=0.151)$.

The estimated coefficients for the dummy variables can be interpreted as the percentage increase in car price derived from the introduction of a new attribute. For instance, those cars with a climate control system are $13 \%$ more expensive, holding the rest of the characteristics constant. Brand effects are computed with respect to Seat, probably the most representative Spanish car manufacturer. The significance of the estimated coefficients shows that there is a brand-quality effect over and above the included car attributes. Mercedes cars appear as the most expensive brand, once the characteristics have been controlled for. In the semi-log formulation, the coefficient for the time dummy variables reveals the variation in the log of the price adjusted by quality change. That is, the antilogarithm of the estimated coefficient for year $t$ can be interpreted as the percentage change in the car price between the base period and period $t$, maintaining quality constant. In our case, the coefficient estimated for year 2005 implies that, holding constant the characteristics, nominal car prices have increased by a factor of 2.31 between 1981 and 2005.

The estimated coefficients for the dummy variables on imported cars clearly showed the process of tariff reductions that took place once Spain joined the European Community in $1986^{14}$. The coefficients were no longer significant after 1992, when the tariff reached zero for Europeans cars. In the preliminary estimations, we include a dummy on imported cars for those years after 1992. However, the coefficients were not

\footnotetext{
${ }^{14}$ The process of tariff reduction started in 1986 and finished in 1992. Over those years taxes on European cars fell from $65 \%$ to zero.
} 
significant. In the final equation therefore, the dummy for imported cars was limited to the 1981-1992 period.

The main problem with the time dummy variable method is that it assumes parameter stability over time. With the aim of relaxing this assumption, we proceeded according to the proposals detailed in section 2 . We began by estimating the most general model, i.e., the yearly regression equations, followed by the adjacent year approach. We then estimated the hedonic function for a moving sample of order 3 and 5, and finally we calculated the coefficients on car attributes as a moving average of the estimated coefficients in the single year equations. Again the order of the moving average was limited to 3 and 5. Table 3 summarises the results of yearly, adjacent year and moving sample estimations ${ }^{15}$.

As is usual, the estimated coefficients in the single year regressions varied considerably from one year to another, and their observed behaviour could not be explained either on economic or on technical grounds. The adjacent period approach reduced the instability of coefficients but still the erratic behaviour of the coefficients could be observed. However, the estimations using order 3 and 5 moving samples smoothed out the changes in the estimated coefficients. To illustrate this fact, in Figure 1 we plotted the estimated coefficients in the adjacent year and order 5 moving sample specifications for two car attributes: engine power (horsepower/weight) and car size.

In order to provide more formal evidence about the advantage of the moving sample approach over the yearly equations and the adjacent year ones we constructed three

\footnotetext{
${ }^{15}$ We estimated 93 different equations. Since presentation of all equations would be too cumbersome, the results are summarised in Table 3.
} 
Additionally, we have constructed a normal distribution for the elasticity of the continuous variables estimated according to the adjacent year approach and the order 3 and 5 moving samples. Figure 2 shows how the precision of the estimation increases when we change from year equations to the moving sample ${ }^{16}$.

The validity of the new proposals needs to be tested against the yearly equation model. Thus, the hypotheses regarding the temporal stability of the characteristic coefficients with respect to the single year equations were tested using the F-test. The results are presented in Table 5. Comparing the yearly regressions with the pooled model, the hypothesis of parameter stability over time is rejected. In contrast, at a $5 \%$ significance level, the hypothesis of equality restrictions both for the adjacent year approach and for

\footnotetext{
${ }^{16}$ A normal distribution has been generated for each estimated elasticity, the mean being the average of the estimated elasticities for each year in the sample and the standard deviation the average of the estimated standard errors. It is interesting to remark that the mean value of the estimated elasticities under the three estimation approaches are very similar but the standard deviations substantially differ.
} 
the order 3 moving sample was not rejected in any of the cases, whereas that for the order 5 moving sample was marginally rejected only in three cases out of 21 .

The second proposal to correct for erraticity in the estimated coefficients consists of calculating the weighted average of annual coefficients, using the inverse of the variance as weights. As was previously stated, when deciding on the order for the moving average, a trade-off exists between the degree of smoothing and the flexibility of the coefficients in accommodating structural changes over time. Given the time span for our data, we propose to use order 3 and order 5 moving averages and test the equality constraints. In this case the test on equality restrictions entails testing equality among coefficients according to the proposal detailed in section 2. For the order 3 moving average, the null hypothesis of stability of the slope coefficients was rejected only in 5 cases out of 745 computed averages, at a significance level of $5 \%$. For the order 5 moving average, the hypothesis was rejected in 12 cases from 667.

At the usual significance levels, the results on equality restrictions support the alternative methodologies suggested in this paper. That is, the procedures based either on moving samples or on moving averages of coefficients allow for temporal changes in the estimated coefficients, as demand or supply curves shift over time, while avoiding the situation where the erratic variation in the coefficients, tied to the multicollinearity problem and to the reduced sample size, hinders their economic interpretation.

\section{Results}

5.1. Computation of quality-adjusted prices 
In the previous section we provided support for alternative methodologies to estimate hedonic equations. Now we turn to the essential objective of hedonic equations; i.e. computing quality-adjusted price indexes or hedonic indexes. The question is: does the methodology used make a difference to the price index in our case? To answer this question we computed the rate of change of the price index applying each alternative procedure.

The hedonic regression in period $t$ has the following form:

$$
\ln \left(p_{i t}\right)=\alpha_{t}+\beta^{\prime} \cdot X_{i t}+\gamma^{\prime} \cdot Z_{i t}+\varepsilon_{i t}
$$

The semi-log formulation makes it possible to define the mean variation of quality adjusted prices as the difference between the variation in the average observed prices minus the variation that can be attributed to the changes in the mean values of each of the $\mathrm{X}$ characteristics and each of the $\mathrm{Z}$ brands for different time periods. Thus, the variation in the index for periods $t$ and $t-1$ will be given by:

$$
\Delta \ln I_{t}=\left(\ln p_{t}-\ln p_{t-1}\right)-\hat{\beta}^{\prime} \cdot\left(\bar{X}_{t}-\bar{X}_{t-1}\right)-\hat{\gamma}^{\prime} \cdot\left(\bar{Z}_{t}-\bar{Z}_{t-1}\right)
$$

This method of calculating the price index is preferred to the usual time dummy variable coefficient for two reasons. Firstly, the functional form of the hedonic equation does not necessarily determine the functional form of the price index. Secondly, it makes it possible to calculate a weighted price index without introducing weights in the estimation procedure ${ }^{17}$.

\footnotetext{
${ }^{17}$ See Triplett (2004, pp.60-61).
} 
In accordance with expression 15 , we computed the price index variation rate for six of the hedonic formulations employed: adjacent year; 3-moving sample; 5-moving sample; 3-moving average of the coefficients of single period estimates, 5-moving average of the coefficients of single period estimates and pooled equation ${ }^{18}$. As can be observed in Figure 3, our findings are that all indexes are remarkably close across alternative methodologies ${ }^{19}$.

The fact to be stressed is that, although the marginal prices for characteristics differ substantially depending on the methodology employed, the rate of variation of the quality-adjusted price index is very similar for all six alternative formulations. The reason for this apparent paradox is that the multicollinearity and the reduced degrees of freedom distort the yearly regression coefficients. However, when adding up the contributions of all explanatory variables, the differences cancel out, so that the behaviour of quality adjusted prices is very similar, irrespectively of the formulation employed to estimate the characteristics.

The previous result can be tested in a more formal way as follows. By comparing the price index for two alternatives, we have:

$d_{i j t}=\Delta \ln \left(I_{i t}\right)-\Delta \ln \left(I_{j t}\right)$

Where, $i$ and $j$ denote different estimation methods. Thus,

$d_{i j t} \rightarrow N\left(0, \sigma_{i j}\right)$

\footnotetext{
${ }^{18}$ When computing the index for the single year equation between years $t$ and $t-1$, it is necessary to choose the reference year. A common option suggested in the literature (Diewert 2003) is to use the arithmetic average of the coefficients estimated in $t$ and $t-1$. This procedure offers very similar results to those obtained when estimating according to adjacent year method. In fact, as Triplett (2004, p.63) argues, one of the earliest empirical regularities found in the hedonic literature is that the adjacent period regression often yields coefficients that are approximately the average of the coefficients estimated from a separate regression in the two periods. This is the reason why the single year approach is not presented.

${ }^{19}$ The moving sample and moving average formulations do not allow the index for the latest years in the sample to be calculated. These values have been forecast by using an AR model.
} 
Consequently,

$$
\sum_{t=2}^{T}\left(\frac{d_{i j t}}{\hat{\sigma}_{i j}}\right)^{2} \rightarrow \chi_{T-1}^{2}
$$

Table 6 summarises the statistic computed for all possible pairs of combinations between alternative estimations. In all cases, the null hypothesis could not be rejected at a high significance level.

To sum up, our contribution to hedonics is a new strategy that can be defined as a compromise solution for estimating the marginal prices for characteristics between two polar alternatives: the time dummy variable model - which assumes that marginal prices for characteristics are constant over time - and single period estimations -that allow estimated coefficients to vary freely year-by-year. In any event, in our study the price indexes based on models with different assumptions about parameter stability are robust to the specified hypothesis.

\subsection{Price indexes behaviour}

Once the methodological issues have been dealt with, this section focuses on the empirical results yielded by the study. The reported results are based on an order 3 moving average equation. Taking into account that equality restriction among the price indexes has not been rejected, the selection of this equation is due to the fact that it provides smoothed coefficients, at the cost of losing only two observations. 
First, we present an analysis of the decomposition of the observed prices for cars according to the different components included in the hedonic equation. Specifically, price variation between period $\mathrm{t}$ and $\mathrm{t}-1,\left(\ln p_{t}-\ln p_{t-1}\right)$, can be decomposed into the sum of the following terms:

$\left(\ln \bar{p}_{t}-\ln \bar{p}_{t-1}\right)=\hat{\beta}^{\prime} \cdot\left(\bar{X}_{t}-\bar{X}_{t-1}\right)+\hat{\gamma}^{\prime} \cdot\left(Z_{t}-Z_{t-1}\right)+\Delta \ln \left(I_{t}\right)$

Where,

$\hat{\beta}^{\prime} \cdot\left(X_{t}-X_{t-1}\right) \quad$ is the variation that can be attributed to the characteristics

$\hat{\gamma}^{\prime} \cdot\left(Z_{t}-Z_{t-1}\right) \quad$ is the variation that can be attributed to the brands

$\Delta \ln \left(I_{t}\right) \quad$ is the hedonic variation computed as in (15)

The hedonic variation in real terms is computed as $\Delta \ln \left(I_{t}\right)-\Delta \ln (C P I)$

The indexes were computed for each year at the mean value of the explanatory variables. Table 7 provides the results. The first and third columns illustrate the rise of the nominal and real (CPI-deflated) car prices. Thus, according to our sample, over the 1981-2005 period, nominal car prices in Spain increased by a factor of 4.4; in real terms the factor falls to 1.2. However, part of the price growth is explained by quality improvements. As can be seen in the fourth column, the quality index, measured by the characteristics included in the equation, increased by a factor of 1.9. The effect of changes in brand composition (fifth column) was almost nil. As a result, it can be seen that the real quality-adjusted price index fell by $40 \%$.

It should be noted that changes in car taxes are included in our hedonic index. The most important changes in taxation were a 9 point increase in the tax rate in 1986 and a 5 point reduction in 1992, which coincided with a fall in the average nominal car price. 
Our approach gives a lower rate of quality-adjusted price increases compared with the rates used by the Spanish statistical agency. This is a common result when applying hedonic regressions. Van Dalen and Bode (2004) estimated a hedonic model for new passenger cars in the Netherlands over the period 1990-1999 that lead to quality corrected price increases between 7.3 and 17.7 percentage points below the official CPI index for new passengers cars, although the latter partially corrects for quality changes. A similar result has been found by Izquierdo et al. (2001) in their study of car prices in Spain during the 1997-2000 period.

\subsection{Quality indexes for groups of characteristics}

Following the same procedure as in price indexes, we have computed quality indexes for the six categories established in Table 1: performance, ease of drive, size, comfort, fuel consumption and safety. Figure 4 plots the temporal profile. The variables representing size show the highest contribution to quality improvement of cars. The index takes value 1 in 1981 and it increases up to 1.19 in 2005 . The growth of this index has to be related to the small size of Spanish cars in 1981, as well as to the existence of other non-observed quality attributes that improve with size. Secondly, the increase in fuel cosnumption has also had a positive effect on quality (1.16 in 2005). The time profile of this variable can be related to the fuel price. Thus, up to 1988 the quality index rose very sharply as a consequence of technical changes introduced by car manufacturers after the energy crises of 1973 and 1979. However, the decline in oil prices in the second half of the eighties slowed down efficiency gains, which picked up again after 1997. Thirdly, during the eighties a steep increase in the quality index related to engine power was observed followed by much lower rates thereafter. This result 
agrees with the findings of previous studies, and can be explained by the improvements in engine efficiency, that allowed far better performance without increasing engine power. Finally, the substantial contribution of those variables representing comfort to the quality of cars should be mentioned. In this case, a certain relationship with Spanish income growth can be observed.

\subsection{Price convergence and economic integration}

Spain joined the European Community in 1986. One of the main arguments put forward to favour the process of economic integration is the consequent increase in competition which in turn translates into efficiency gains. Although it is difficult to find situations where this hypothesis can be directly tested, we should expect a convergence in qualityadjusted prices favoured by a higher level of market competition. We address this issue by computing the sigma convergence for different definitions of car prices. Figure 5 provides the results.

For observed real prices, no clear pattern emerges. Despite the process of economic integration, price dispersion oscillates without a defined trend. However, when adjusting prices for quality changes, a clear process of convergence can be seen between 1986 and 1992, corresponding to the period of tariff reduction. This result is even clearer when prices are adjusted for both quality and brand changes. Hence, while for observed prices there was no process of convergence, for hedonic prices, which are the relevant ones in terms of measuring the degree of market competition, a clear reduction of price dispersion emerged. The reason lies in the substantial increase in high quality car imports with significant quality improvements with respect to Spanish cars, which 
resulted in a wider dispersion of observed prices, whereas the dispersion in qualityadjusted prices narrowed.

The effects of economic integration on the level of market competition can also be analysed by re-estimating the pooled regression equation including annual dummy variables on imported cars to capture its impact on prices ${ }^{20}$. The estimated coefficients for these variables can be interpreted as the effect of market integration, and as such can be related to the degree of dispersion in the price variable. A simple scatter diagram illustrates the correlation between the effect of tariff reduction, through the estimated coefficients, and the $\sigma$-convergence. Figure 6 shows a weak relationship between tariff reduction and $\sigma$-convergence for observed car prices, while a strong negative correlation appears when prices are adjusted for quality changes.

\section{Conclusions}

The aim of this paper has been to estimate hedonic prices for a manufactured good -the car- that has been subject to significant technical change.

From a methodological point of view, we have addressed one of the limitations of hedonic regressions, the instability of coefficients over time. As long as the estimated coefficients can be interpreted as marginal prices for characteristics, an accurate estimation of them is needed. It is common in the literature to consider two polar assumptions. On the one hand, the pooled regression model assumes constant coefficients over time. In this case, the coefficients usually take the expected sign and

\footnotetext{
${ }^{20}$ In the original specification these variables were limited to the 1981-1992 period.
} 
are precisely estimated, but parameter equality is very often rejected by the data. On the other hand, unrestricted single year equations are estimated, which frequently generate very erratic and poorly estimated coefficients. The adjacent year is the usual approach to address this problem. Nonetheless, erraticity is still present. Our study proposes two solutions consisting in constructing a moving sample of the observations and a weighted moving average of the coefficients estimated in the single year equations. In both cases, the new alternative makes it possible to allow for annual changes in marginal prices of characteristics without imposing constraints that would be rejected by the data.

In relation to the empirical results, two issues can be emphasised. Firstly, CPI deflated car prices in Spain rose by $20 \%$ between 1981 and 2005 . However, once quality improvements are taken into account, real car prices fell by $40 \%$. This result is common in the literature that computes hedonic prices for goods subject to rapid technological progress and quality improvements. Additionally, it has to be stressed that the $40 \%$ drop is robust to the alternative estimation procedures employed in the study.

Secondly, for observed car prices there is no general trend of sigma convergence over the sample period; however, once quality improvements are taken into account, a clear trend in $\sigma$-convergence emerges between 1986 and 1992. This result has to be related to the tariff reduction following Spain's integration in the EC, which led to a more competitive market. 
Arguea, N.M., C. Hsiao, and G.A. Taylor (1994) Estimating consumer preferences using market data -an application to US automobile demand, Journal of Applied Econometrics, 9, 1-18.

Bajic, V. (1993) Automobiles and implicit markets: an estimate of structural demand model for automobile characteristics, Applied Economics, 2, 541-551.

Berndt R.E. (1991) The Practice of Econometrics: classic and contemporary. Reading, Mass.: Addison-Wesley Publishing Company, pp. 102-149.

Berndt, R.E. and N.J. Rappaport (2003) Hedonics for personal computers: a reexamination of selected econometric issues. $R \& D$, Education and productivity, an international conference in memory of Zvi Griliches. Paris, august 25-27. Draft manuscript: research still in progress.

Dalen, J. Van and B. Bodie (2004) Quality-corrected price indices: the case of the Dutch new passenger car market 1990-1999, Applied Economics, 34, 11691197.

Deaton, A. (1997) The analysis of households surveys: A microeconometric approach to development policy. The Johns Hopkins University Press.

Diewert, E. (2003) Hedonic regressions: a review of some unresolved issues, $7^{\text {th }}$ Meeting of the Ottawa Group. Paris, 27-29 May 2003.

Feenstra, R. C. (1995) Exact hedonic price indexes, The Review of Economics and Statistics, 77, 634-653.

Granger, C.W.J and P. Newbold (1986) Forecasting economic time series. 2nd ed. Orlando: Academic Press.

Houthakker, H.S. (1952) Compensated changes in quantities and qualities consumed, The Review of Economic Studies, 19, 155-164. 
Izquierdo, M., O. Licandro and A. Maydeu (2001) Mejoras de calidad e índices de precios del automóvil en España, Madrid: Banco de España, Estudios Económicos, 72.

Lancaster, K. J. (1966) A new approach to consumer theory, Journal of Political Economy, 74, 132-157.

Murray, J. and N. Sarantis (1999) Price-quality relations and hedonic price indexes for cars in the United Kingdom, International Journal of the Economics and Business, 6, 5-27.

Ohta, M. and Z. Griliches (1986) Automobile prices and quality: did the gasoline price increase change consumer tastes in the U.S.? Journal of Business and Economic Statistics, 4, 187-198.

Pakes, A. (2003) A reconsideration of hedonic price indexes with an application to PC's, American Economic Review, 93, 1578-1596.

Pakes, A. (2004) Hedonics and the consumer price index. Mimeo.

Raff, D.M.G and M. Trajtenberg (1995) Quality adjusted prices for the American automobile industry: 1906-1940. Cambridge, MA: NBER, Working Paper 5035.

Reis, H.J. and J.M.C. Santos Silva (2002) Hedonic prices indexes for new passenger cars in Portugal (1997-2001). Lisbon: Banco de Portugal, Working Paper 10-02.

Requena-Silvente, F. and J. Walker (2006) Calculating hedonic price indices with unobserved product attributes: an application to the UK car market, Economica, on line publication.

Rosen, S. (1974) Hedonic prices and implicit markets: product differentiation in pure competition, Journal of Political Economy, 82, 34-55. 
1

2

3

4

5

6

7

8

9

10

11

12

13

14

15

16

17

18

19

20

21

22

23

24

25

26

27

28

29

30

31

32

33

34

35

36

37

38

39

40

41

42

43

44

45

46

47

48

49

50

51

52

53

54

55

56

57

58

59

60

Triplett, J. (2004) Handbook on hedonic indexes and quality adjustments in price indexes: special application to information technology products. Paris: OECD, STI Working Paper 2004/9.

\section{Acknowledgements}

This work has benefited from a research grant from the Spanish Ministerio de Educación y Ciencia (SEJ 2006-14849). The authors thank A.I. Guerra for her support in collecting the data and the Instituto de Estudios de Automoción for providing the information on automobile sales and to J. Asensio for his comments. 
Table 1. Variable definition for vehicle characteristics

\begin{tabular}{|l|l|}
\hline Performance & $\begin{array}{l}\text { Displacement (CID, cubic inch displacement) } \\
\text { Horsepower / weight }\end{array}$ \\
\hline Ease of drive & $\begin{array}{l}\text { Power assisted steering (dummy variable) } \\
\text { Automatic gear (dummy variable) }\end{array}$ \\
\hline Size & $\begin{array}{l}\text { Volume (length*width*height) } \\
\text { Minivan (dummy variable) }\end{array}$ \\
\hline Comfort & $\begin{array}{l}\text { Number of doors } \\
\text { Air conditioning (dummy variable) } \\
\text { Climate control (dummy variable) } \\
\text { Electric windows (dummy variable) }\end{array}$ \\
\hline Fuel efficiency & $\begin{array}{l}\text { Fuel consumption (litres per 100 km / horsepower) } \\
\text { Diesel (dummy variable) }\end{array}$ \\
\hline Safety features & \begin{tabular}{l} 
Antilock Braking System (ABS) (dummy variable) \\
\hline
\end{tabular}
\end{tabular}

Table 2. Selection of the functional form

\begin{tabular}{lll}
\hline Functional form & L*-value & Schwarz criterion \\
\hline Box-Cox $\left(\lambda_{\text {l.h.s }}=0.03\right)$ & -26403.48 & -26699.33 \\
$\quad\left(\lambda_{\text {r.h.s }}=1.05\right)$ & \\
Semi-log & -26404.79 & -26696.84 \\
\hline
\end{tabular}

Schwarz criterion has been computed as $L^{*}-\frac{k}{2} \ln (N)$, where $\mathrm{k}$ is the number of estimated parameters and $\mathrm{N}$ the sample size. 


\section{Table 3. Estimation results}

\begin{tabular}{|c|c|c|c|c|c|c|c|c|c|c|c|c|c|c|c|c|}
\hline & \multicolumn{3}{|c|}{ Yearly equations } & \multicolumn{4}{|c|}{ Adjacent year } & \multicolumn{4}{|c|}{ Third order sample average } & \multicolumn{4}{|c|}{ Fith order sample average } & \multirow[b]{2}{*}{$\begin{array}{l}\text { No. } \\
\text { obs. }\end{array}$} \\
\hline & $\begin{array}{c}\text { No. } \\
\text { regressors }\end{array}$ & $\begin{array}{c}\text { No.sign. } \\
\text { coef } \\
(5 \%)\end{array}$ & $\begin{array}{l}\text { Standard } \\
\text { error }\end{array}$ & $\begin{array}{l}\text { No. } \\
\text { obs. }\end{array}$ & $\begin{array}{c}\text { No. } \\
\text { regressors }\end{array}$ & $\begin{array}{l}\text { No.sign. } \\
\text { coef }(5 \%)\end{array}$ & $\begin{array}{l}\text { Standard } \\
\text { error }\end{array}$ & $\begin{array}{l}\text { No. } \\
\text { obs. }\end{array}$ & $\begin{array}{c}\text { No. } \\
\text { regressors }\end{array}$ & $\begin{array}{c}\text { Jo.sign.coef } \\
(5 \%)\end{array}$ & $\begin{array}{l}\text { Standard } \\
\text { error }\end{array}$ & $\begin{array}{l}\text { No. } \\
\text { obs. }\end{array}$ & $\begin{array}{c}\text { No. } \\
\text { regressors }\end{array}$ & $\begin{array}{c}\text { No.sign. } \\
\text { coef } \\
(5 \%)\end{array}$ & $\begin{array}{l}\text { Standard } \\
\text { error }\end{array}$ & \\
\hline 1981 & 20 & 10 & 0.05425 & 47 & - & - & - & - & - & - & - & - & - & - & - & - \\
\hline 1982 & 22 & 12 & 0.06895 & 58 & 24 & 15 & 0.05991 & 105 & 28 & 19 & 0.06504 & 168 & - & - & - & - \\
\hline 1983 & 24 & 13 & 0.06757 & 63 & 26 & 16 & 0.06709 & 121 & 28 & 21 & 0.07150 & 189 & 33 & 26 & 0.07241 & 301 \\
\hline 1984 & 24 & 12 & 0.07629 & 68 & 26 & 18 & 0.06927 & 131 & 29 & 22 & 0.06793 & 196 & 35 & 28 & 0.07076 & 318 \\
\hline 1985 & 25 & 13 & 0.06671 & 65 & 27 & 17 & 0.06890 & 133 & 31 & 24 & 0.06831 & 197 & 36 & 29 & 0.06773 & 329 \\
\hline 1986 & 27 & 15 & 0.06162 & 64 & 29 & 20 & 0.06531 & 129 & 32 & 24 & 0.06454 & 198 & 36 & 29 & 0.06829 & 332 \\
\hline 1987 & 28 & 11 & 0.06485 & 69 & 30 & 19 & 0.05843 & 133 & 32 & 23 & 0.06158 & 199 & 37 & 31 & 0.06575 & 331 \\
\hline 1988 & 27 & 13 & 0.07175 & 66 & 30 & 19 & 0.06299 & 135 & 33 & 22 & 0.06223 & 202 & 37 & 28 & 0.06307 & 329 \\
\hline 1989 & 28 & 15 & 0.06490 & 67 & 30 & 19 & 0.06261 & 133 & 32 & 22 & 0.06201 & 196 & 38 & 27 & 0.06240 & 335 \\
\hline 1990 & 27 & 12 & 0.06650 & 63 & 30 & 21 & 0.06084 & 130 & 33 & 22 & 0.06136 & 200 & 39 & 30 & 0.06457 & 337 \\
\hline 1991 & 28 & 15 & 0.05830 & 70 & 29 & 17 & 0.06202 & 133 & 34 & 23 & 0.06051 & 204 & 39 & 29 & 0.06126 & 342 \\
\hline 1992 & 30 & 15 & 0.06581 & 71 & 32 & 19 & 0.05776 & 141 & 34 & 25 & 0.05547 & 212 & 38 & 30 & 0.05884 & 350 \\
\hline 1993 & 29 & 20 & 0.05253 & 71 & 31 & 25 & 0.05640 & 142 & 34 & 27 & 0.05662 & 217 & 40 & 32 & 0.05607 & 364 \\
\hline 1994 & 31 & 18 & 0.05947 & 75 & 32 & 25 & 0.05322 & 146 & 36 & 29 & 0.05269 & 223 & 40 & 32 & 0.06127 & 374 \\
\hline 1995 & 34 & 18 & 0.06007 & 77 & 35 & 25 & 0.05449 & 152 & 37 & 27 & 0.06281 & 232 & 39 & 33 & 0.06598 & 387 \\
\hline 1996 & 35 & 11 & 0.07541 & 80 & 36 & 22 & 0.06693 & 157 & 37 & 27 & 0.07050 & 241 & 42 & 34 & 0.06871 & 409 \\
\hline 1997 & 35 & 14 & 0.08161 & 84 & 36 & 23 & 0.07289 & 164 & 40 & 28 & 0.07061 & 257 & 42 & 34 & 0.06852 & 429 \\
\hline 1998 & 38 & 20 & 0.06002 & 93 & 37 & 26 & 0.06994 & 177 & 40 & 29 & 0.06514 & 272 & 42 & 32 & 0.06881 & 449 \\
\hline 1999 & 38 & 22 & 0.06057 & 95 & 39 & 25 & 0.05609 & 188 & 40 & 26 & 0.06093 & 285 & 43 & 30 & 0.06848 & 472 \\
\hline 2000 & 38 & 15 & 0.07541 & 97 & 39 & 23 & 0.06384 & 192 & 41 & 26 & 0.06728 & 295 & 43 & 31 & 0.06455 & 492 \\
\hline 2001 & 39 & 14 & 0.07738 & 103 & 40 & 21 & 0.07109 & 200 & 41 & 24 & 0.06678 & 304 & 43 & 29 & 0.06488 & 505 \\
\hline 2002 & 39 & 17 & 0.06486 & 104 & 40 & 22 & 0.06656 & 207 & 41 & 22 & 0.06370 & 313 & 43 & 25 & 0.06599 & 523 \\
\hline 2003 & 39 & 20 & 0.06513 & 106 & 40 & 24 & 0.05968 & 210 & 41 & 26 & 0.06256 & 323 & 43 & 26 & 0.06770 & 527 \\
\hline 2004 & 39 & 19 & 0.06846 & 113 & 40 & 22 & 0.06480 & 219 & 41 & 22 & 0.06709 & 320 & - & - & - & - \\
\hline 2005 & 36 & 15 & 0.07580 & 101 & 37 & 20 & 0.07097 & 214 & - & - & - & - & - & - & - & - \\
\hline
\end{tabular}


Table 4. Comparison of coefficients' instability for different estimation approaches

\begin{tabular}{|c|c|c|c|c|c|c|c|c|c|c|c|c|}
\hline & \multicolumn{4}{|c|}{ Standard error of the characteristic elasticity } & \multicolumn{4}{|c|}{$\begin{array}{l}\text { Standard error of the AR model for the } \\
\text { estimated elasticities }\end{array}$} & \multicolumn{4}{|c|}{$\begin{array}{l}\text { Number of wrong signs for the estimatec } \\
\text { coefficients }\end{array}$} \\
\hline & $\begin{array}{c}\text { Yearly } \\
\text { equations }\end{array}$ & $\begin{array}{c}\text { Adjacent } \\
\text { years }\end{array}$ & $\begin{array}{c}\text { 3rd } \\
\text { order }\end{array}$ & $\begin{array}{l}5 \text { th } \\
\text { order }\end{array}$ & $\begin{array}{c}\text { Yearly } \\
\text { equations }\end{array}$ & $\begin{array}{l}\text { Adjacent } \\
\text { years }\end{array}$ & $\begin{array}{c}\text { 3rd } \\
\text { order }\end{array}$ & $\begin{array}{l}5 \text { th } \\
\text { order }\end{array}$ & $\begin{array}{c}\text { Yearly } \\
\text { equations }\end{array}$ & $\begin{array}{l}\text { Adjacent } \\
\text { years }\end{array}$ & $\begin{array}{c}\text { 3rd } \\
\text { order }\end{array}$ & $\begin{array}{c}\text { 5th } \\
\text { order }\end{array}$ \\
\hline Displacement & 0.1098 & 0.0703 & 0.0555 & 0.0426 & 0.0963 & 0.0673 & 0.0563 & 0.0330 & 1 & 0 & 0 & 0 \\
\hline H.P./weight & 0.1263 & 0.0804 & 0.0633 & 0.0483 & 0.1091 & 0.0858 & 0.0515 & 0.0312 & 1 & 1 & 0 & 0 \\
\hline Volume & 0.1734 & 0.1110 & 0.0877 & 0.0671 & 0.1516 & 0.0990 & 0.0671 & 0.0390 & 0 & 0 & 0 & 0 \\
\hline
\end{tabular}


Table 5. F-test general model (yearly regressions) versus constrained models

\begin{tabular}{|c|c|c|c|c|c|c|c|c|}
\hline & \multicolumn{2}{|c|}{ Adjacent year } & \multicolumn{2}{|c|}{$\begin{array}{c}\text { 3rd order sample } \\
\text { average }\end{array}$} & \multicolumn{2}{|c|}{$\begin{array}{c}\text { 5th order sample } \\
\text { average }\end{array}$} & \multicolumn{2}{|c|}{ Pooled equation } \\
\hline & Fstatistic & $\begin{array}{c}\mathrm{F} \text { critical } \\
\text { value }(5 \%)\end{array}$ & Fstatistic & $\begin{array}{c}\mathrm{F} \text { critical } \\
\text { value }(5 \%)\end{array}$ & Fstatistic & $\begin{array}{c}\mathrm{F} \text { critical } \\
\text { value }(5 \%)\end{array}$ & Fstatistic & $\begin{array}{c}\mathrm{F} \text { critical } \\
\text { value }(5 \%)\end{array}$ \\
\hline $1981-2005$ & - & - & - & - & - & - & 1.67 & 1.00 \\
\hline 1982 & 0.50 & 1.75 & 1.02 & 1.50 & - & - & & \\
\hline 1983 & 0.76 & 1.75 & 1.02 & 1.43 & 1.43 & 1.22 & & \\
\hline 1984 & 0.61 & 1.75 & 0.72 & 1.32 & 1.20 & 1.22 & & \\
\hline 1985 & 0.58 & 1.70 & 0.94 & 1.32 & 0.99 & 1.22 & & \\
\hline 1986 & 1.04 & 1.70 & 1.00 & 1.43 & 0.96 & 1.22 & & \\
\hline 1987 & 0.37 & 1.70 & 0.53 & 1.43 & 0.96 & 1.22 & & \\
\hline 1988 & 0.37 & 1.70 & 0.51 & 1.43 & 0.73 & 1.22 & & \\
\hline 1989 & 0.32 & 1.70 & 0.45 & 1.43 & 0.73 & 1.22 & & \\
\hline 1990 & 0.43 & 1.70 & 0.80 & 1.43 & 0.91 & 1.22 & & \\
\hline 1991 & 0.98 & 1.70 & 0.70 & 1.43 & 0.95 & 1.22 & & \\
\hline 1992 & 0.40 & 1.65 & 0.59 & 1.32 & 0.84 & 1.22 & & \\
\hline 1993 & 0.60 & 1.65 & 0.69 & 1.32 & 0.69 & 1.22 & & \\
\hline 1994 & 0.54 & 1.65 & 0.48 & 1.32 & 0.83 & 1.22 & & \\
\hline 1995 & 0.31 & 1.65 & 0.75 & 1.22 & 0.89 & 1.00 & & \\
\hline 1996 & 0.82 & 1.65 & 0.77 & 1.22 & 1.06 & 1.00 & & \\
\hline 1997 & 0.46 & 1.65 & 0.85 & 1.22 & 1.06 & 1.00 & & \\
\hline 1998 & 0.81 & 1.55 & 0.77 & 1.22 & 0.85 & 1.00 & & \\
\hline 1999 & 0.46 & 1.55 & 0.52 & 1.22 & 0.75 & 1.00 & & \\
\hline 2000 & 0.45 & 1.55 & 0.58 & 1.22 & 0.68 & 1.00 & & \\
\hline 2001 & 0.40 & 1.50 & 0.46 & 1.22 & 0.64 & 1.00 & & \\
\hline 2002 & 0.43 & 1.50 & 0.45 & 1.22 & 0.63 & 1.00 & & \\
\hline 2003 & 0.30 & 1.50 & 0.60 & 1.22 & 0.75 & 1.00 & & \\
\hline 2004 & 0.71 & 1.50 & 0.71 & 1.22 & - & - & & \\
\hline 2005 & 0.94 & 1.50 & - & - & - & - & & \\
\hline
\end{tabular}


Table 6 . Test of price indexes equality

Adjacent year vs $3^{\text {rd }}$ order sample average

Adjacent year vs $3^{\text {rd }}$ order moving average of the coefficients

$$
\chi^{2} \text { statistic }
$$

d.f. P-Value

23.51

23

0.431

23.34

0.441

Adjacent year vs $5^{\text {th }}$ order sample average

23.37

23

0.381

Adjacent year vs $5^{\text {th }}$ order moving average of the coefficients

26.76

22

0.220

Adjacent year vs pooled equation

23.33

22

0.442

$3^{\text {rd }}$ order sample average vs pooled equation

$3^{\text {rd }}$ order moving average of coef. vs pooled equation

22.28

23

0.503

23.02

23

0.460

$5^{\text {th }}$ order sample average vs pooled equation

21.12

23

0.513

$5^{\text {th }}$ order moving average of coef. vs pooled equation

22.70

22

0.419

$3^{\text {rd }}$ order sample average vs $3^{\text {rd }}$ order moving average of coef.

24.95

22

0.353

$3^{\text {rd }}$ order sample average vs $5^{\text {th }}$ order sample average

22.44

23

0.434

$3^{\text {rd }}$ order sample average vs $5^{\text {th }}$ order moving average of coef.

26.96

22

0.213

$3^{\text {rd }}$ order moving average of coef. vs $5^{\text {th }}$ order sample average

20.25

22

0.567

$3^{\text {rd }}$ order moving average of coef. vs $5^{\text {th }}$ order moving average

23.25

22 of coef.

$5^{\text {th }}$ order sample average vs $5^{\text {th }}$ order moving average of coef.

23.53

0.388

0.372

Table 7. Decomposition of car price index into different components

\begin{tabular}{lccccccc}
\hline & $\begin{array}{c}\text { Price } \\
\text { (nominal) }\end{array}$ & CPI & $\begin{array}{c}\text { Price } \\
\text { (real) }\end{array}$ & $\begin{array}{c}\text { Characteristics } \\
\text { index }\end{array}$ & $\begin{array}{c}\text { Brand } \\
\text { index }\end{array}$ & $\begin{array}{c}\text { Hedonic } \\
\text { index }\end{array}$ & $\begin{array}{c}\text { Hedonic } \\
\text { index (real) }\end{array}$ \\
\hline 1981 & 1.000 & 1.000 & 1.000 & 1.000 & 1.000 & 1.000 & 1.000 \\
1982 & 1.168 & 1.144 & 1.021 & 1.026 & 1.013 & 1.125 & 0.983 \\
1983 & 1.449 & 1.283 & 1.129 & 1.050 & 1.033 & 1.336 & 1.041 \\
1984 & 1.621 & 1.428 & 1.135 & 1.076 & 1.043 & 1.446 & 1.012 \\
1985 & 1.811 & 1.554 & 1.165 & 1.105 & 1.052 & 1.558 & 1.002 \\
1986 & 1.960 & 1.691 & 1.159 & 1.133 & 1.050 & 1.647 & 0.974 \\
1987 & 2.156 & 1.780 & 1.212 & 1.171 & 1.043 & 1.765 & 0.992 \\
1988 & 2.379 & 1.866 & 1.275 & 1.212 & 1.067 & 1.841 & 0.987 \\
1989 & 2.467 & 1.992 & 1.238 & 1.247 & 1.066 & 1.856 & 0.932 \\
1990 & 2.603 & 2.126 & 1.224 & 1.282 & 1.080 & 1.880 & 0.884 \\
1991 & 2.661 & 2.252 & 1.181 & 1.339 & 1.072 & 1.852 & 0.822 \\
1992 & 2.700 & 2.386 & 1.132 & 1.394 & 1.080 & 1.794 & 0.752 \\
1993 & 2.818 & 2.495 & 1.129 & 1.404 & 1.079 & 1.859 & 0.745 \\
1994 & 2.947 & 2.613 & 1.128 & 1.426 & 1.077 & 1.919 & 0.734 \\
1995 & 3.110 & 2.735 & 1.137 & 1.438 & 1.054 & 2.050 & 0.750 \\
1996 & 3.246 & 2.832 & 1.146 & 1.475 & 1.046 & 2.104 & 0.743 \\
1997 & 3.336 & 2.888 & 1.155 & 1.500 & 1.049 & 2.120 & 0.734 \\
1998 & 3.393 & 2.941 & 1.154 & 1.559 & 1.051 & 2.072 & 0.705 \\
1999 & 3.532 & 3.009 & 1.174 & 1.602 & 1.057 & 2.086 & 0.693 \\
2000 & 3.525 & 3.112 & 1.133 & 1.626 & 1.048 & 2.069 & 0.665 \\
2001 & 3.745 & 3.224 & 1.162 & 1.727 & 1.044 & 2.077 & 0.644 \\
2002 & 3.939 & 3.323 & 1.185 & 1.793 & 1.046 & 2.101 & 0.632 \\
2003 & 4.048 & 3.424 & 1.182 & 1.825 & 1.044 & 2.124 & 0.620 \\
2004 & 4.171 & 3.528 & 1.182 & 1.878 & 1.043 & 2.131 & 0.604 \\
2005 & 4.351 & 3.614 & 1.204 & 1.934 & 1.045 & 2.153 & 0.596 \\
\hline
\end{tabular}

From equation (15) price indexes were obtained by adding cumulative log differences of prices and then taking antilogs. 
Table A.1 Descriptive statistics

\begin{tabular}{lccc}
\hline & No. observations & $\begin{array}{c}\text { Average Price } \\
\text { (euros) } \\
\text { (CPl-deflated) }\end{array}$ & Std. Dev. \\
1981 & 47 & 16478.5 & 9097.3 \\
1982 & 58 & 16757.1 & 8802.0 \\
1983 & 63 & 18807.0 & 10531.9 \\
1984 & 68 & 18928.6 & 10393.4 \\
1985 & 65 & 19484.2 & 10718.7 \\
1986 & 64 & 19029.9 & 9919.8 \\
1987 & 69 & 19624.6 & 9650.7 \\
1988 & 66 & 20664.3 & 9826.0 \\
1989 & 67 & 19859.2 & 8811.7 \\
1990 & 63 & 19470.4 & 8131.4 \\
1991 & 70 & 18784.8 & 7785.2 \\
1992 & 71 & 18148.7 & 7860.2 \\
1993 & 71 & 18475.3 & 9108.6 \\
1994 & 75 & 18625.9 & 9672.9 \\
1995 & 77 & 18406.5 & 8382.2 \\
1996 & 80 & 18382.7 & 8061.0 \\
1997 & 84 & 18507.4 & 8048.0 \\
1998 & 93 & 18621.2 & 8348.8 \\
1999 & 95 & 19164.8 & 9219.5 \\
2000 & 97 & 18319.1 & 8329.8 \\
2001 & 103 & 18827.7 & 8432.8 \\
2002 & 104 & 19187.1 & 8562.3 \\
2003 & 106 & 19176.8 & 8605.0 \\
2004 & 113 & 19039.5 & 8225.6 \\
2005 & 101 & 19271.6 & 7980.2 \\
\hline & & &
\end{tabular}


Table A.2. Estimation results for the pooled equation

Dependent Variable: LOG(Price)

Included observations: 1970

White Heteroskedasticity-Consistent Standard Errors \& Covariance

\begin{tabular}{|c|c|c|c|c|}
\hline Variable & Coefficient & Std. Error & t-Statistic & Prob. \\
\hline $\mathrm{C}$ & 12.33359 & 0.049774 & 247.7927 & 0.0000 \\
\hline DISPLACEMENT & 0.000222 & 1.08E-05 & 20.49526 & 0.0000 \\
\hline H.P.MEIGHT & 2.301612 & 0.247389 & 9.303607 & 0.0000 \\
\hline VOLUME & 0.091077 & 0.003050 & 29.85688 & 0.0000 \\
\hline FUEL CONSUMPTION & -2.067027 & 0.183303 & -11.27656 & 0.0000 \\
\hline DIESEL & 0.069964 & 0.008492 & 8.238396 & 0.0000 \\
\hline MINIVAN & 0.039537 & 0.016749 & 2.360549 & 0.0183 \\
\hline № DOORS & 0.029148 & 0.005915 & 4.928121 & 0.0000 \\
\hline AIR CONDITIONED & 0.053243 & 0.006215 & 8.566656 & 0.0000 \\
\hline CLIMATE CONTROL & 0.127339 & 0.007673 & 16.59570 & 0.0000 \\
\hline ABS & 0.046201 & 0.006698 & 6.897887 & 0.0000 \\
\hline ASSITED STEERING & 0.067912 & 0.006651 & 10.21149 & 0.0000 \\
\hline ELECTRIC WINDOWS & 0.025584 & 0.006178 & 4.141281 & 0.0000 \\
\hline AUTOMATIC GEAR & 0.085218 & 0.017102 & 4.982959 & 0.0000 \\
\hline ALFA ROMEO & 0.091467 & 0.017487 & 5.230558 & 0.0000 \\
\hline AUDI & 0.258700 & 0.011970 & 21.61241 & 0.0000 \\
\hline AUSTIN & -0.074346 & 0.025075 & -2.964914 & 0.0031 \\
\hline BMW & 0.346397 & 0.010389 & 33.34168 & 0.0000 \\
\hline CHRYSLER & -0.233620 & 0.021121 & -11.06121 & 0.0000 \\
\hline CITROEN & 0.043901 & 0.009586 & 4.579825 & 0.0000 \\
\hline DAEWOO & -0.114095 & 0.015723 & -7.256535 & 0.0000 \\
\hline FIAT & 0.008876 & 0.011847 & 0.749286 & 0.4538 \\
\hline FORD & 0.034471 & 0.008564 & 4.024977 & 0.0001 \\
\hline HONDA & 0.089910 & 0.018446 & 4.874273 & 0.0000 \\
\hline HYUNDAI & -0.142778 & 0.011942 & -11.95573 & 0.0000 \\
\hline $\mathrm{KIA}$ & -0.267411 & 0.044292 & -6.037499 & 0.0000 \\
\hline LANCIA & 0.098621 & 0.012422 & 7.939430 & 0.0000 \\
\hline MAZDA & 0.035517 & 0.015353 & 2.313313 & 0.0208 \\
\hline MERCEDES & 0.414736 & 0.011592 & 35.77729 & 0.0000 \\
\hline MITSUBISHI & 0.054551 & 0.023226 & 2.348656 & 0.0189 \\
\hline NISSAN & 0.030624 & 0.011925 & 2.568030 & 0.0103 \\
\hline OPEL & 0.082621 & 0.008827 & 9.360237 & 0.0000 \\
\hline PEUGEOT & 0.057520 & 0.008135 & 7.070261 & 0.0000 \\
\hline RENAULT & 0.007337 & 0.007427 & 0.987918 & 0.3233 \\
\hline ROVER & 0.043062 & 0.015401 & 2.796093 & 0.0052 \\
\hline SAAB & 0.197645 & 0.015198 & 13.00467 & 0.0000 \\
\hline SKODA & -0.061187 & 0.020247 & -3.021983 & 0.0025 \\
\hline TALBOT & -0.020536 & 0.009720 & -2.112741 & 0.0348 \\
\hline TOYOTA & 0.045968 & 0.012418 & 3.701838 & 0.0002 \\
\hline VOLVO & 0.227725 & 0.013648 & 16.68590 & 0.0000 \\
\hline VOLKSWAGEN & 0.118445 & 0.008642 & 13.70599 & 0.0000 \\
\hline
\end{tabular}




\begin{tabular}{|c|c|c|c|c|}
\hline YEAR82 & 0.106147 & 0.018453 & 5.752221 & 0.0000 \\
\hline YEAR83 & 0.261728 & 0.017167 & 15.24589 & 0.0000 \\
\hline YEAR84 & 0.339597 & 0.016736 & 20.29105 & 0.0000 \\
\hline YEAR85 & 0.406745 & 0.017252 & 23.57620 & 0.0000 \\
\hline YEAR86 & 0.498870 & 0.017538 & 28.44517 & 0.0000 \\
\hline YEAR87 & 0.567498 & 0.016520 & 34.35153 & 0.0000 \\
\hline YEAR88 & 0.624455 & 0.018241 & 34.23388 & 0.0000 \\
\hline YEAR89 & 0.645247 & 0.018856 & 34.22006 & 0.0000 \\
\hline YEAR90 & 0.679791 & 0.018422 & 36.90009 & 0.0000 \\
\hline YEAR91 & 0.683766 & 0.017354 & 39.40096 & 0.0000 \\
\hline YEAR92 & 0.679761 & 0.019555 & 34.76090 & 0.0000 \\
\hline YEAR93 & 0.731340 & 0.017146 & 42.65282 & 0.0000 \\
\hline YEAR94 & 0.763649 & 0.017163 & 44.49353 & 0.0000 \\
\hline YEAR95 & 0.818267 & 0.017397 & 47.03626 & 0.0000 \\
\hline YEAR96 & 0.840995 & 0.017872 & 47.05540 & 0.0000 \\
\hline YEAR97 & 0.846782 & 0.018356 & 46.13110 & 0.0000 \\
\hline YEAR98 & 0.810593 & 0.017363 & 46.68580 & 0.0000 \\
\hline YEAR99 & 0.809771 & 0.017577 & 46.07055 & 0.0000 \\
\hline YEAR00 & 0.798102 & 0.017887 & 44.61910 & 0.0000 \\
\hline YEAR01 & 0.800529 & 0.018220 & 43.93748 & 0.0000 \\
\hline YEAR02 & 0.813099 & 0.018027 & 45.10523 & 0.0000 \\
\hline YEAR03 & 0.825567 & 0.018300 & 45.11407 & 0.0000 \\
\hline YEAR04 & 0.829190 & 0.018550 & 44.69939 & 0.0000 \\
\hline YEAR05 & 0.837513 & 0.018972 & 44.14556 & 0.0000 \\
\hline YEAR81*IMPORT & 0.264849 & 0.042542 & 6.225597 & 0.0000 \\
\hline YEAR82* IMPORT & 0.264331 & 0.034747 & 7.607373 & 0.0000 \\
\hline YEAR83* IMPORT & 0.271647 & 0.024829 & 10.94067 & 0.0000 \\
\hline YEAR84* IMPORT & 0.272940 & 0.024230 & 11.26461 & 0.0000 \\
\hline YEAR85* IMPORT & 0.253548 & 0.021787 & 11.63772 & 0.0000 \\
\hline YEAR86* IMPORT & 0.173231 & 0.020021 & 8.652421 & 0.0000 \\
\hline YEAR87* IMPORT & 0.137589 & 0.017780 & 7.738514 & 0.0000 \\
\hline YEAR88* IMPORT & 0.113397 & 0.020192 & 5.615971 & 0.0000 \\
\hline YEAR89*IMPORT & 0.091651 & 0.018818 & 4.870388 & 0.0000 \\
\hline YEAR90* IMPORT & 0.053550 & 0.017336 & 3.088959 & 0.0020 \\
\hline YEAR91* IMPORT & 0.045937 & 0.015027 & 3.056973 & 0.0023 \\
\hline YEAR92* IMPORT & 0.019186 & 0.018042 & 1.063358 & 0.2878 \\
\hline & 0.982608 & Mean dependent var & & 14.58690 \\
\hline sted R-squared & 0.981910 & S.D. dependent var & & 0.561995 \\
\hline of regression & 0.075588 & Akaike info criterion & & -2.288733 \\
\hline squared resid & 10.81578 & Schwarz criterion & & -2.070406 \\
\hline ikelihood & 2331.402 & F-statistic & & 1407.247 \\
\hline
\end{tabular}


Figure 1. Estimated coefficients for two alternative specifications
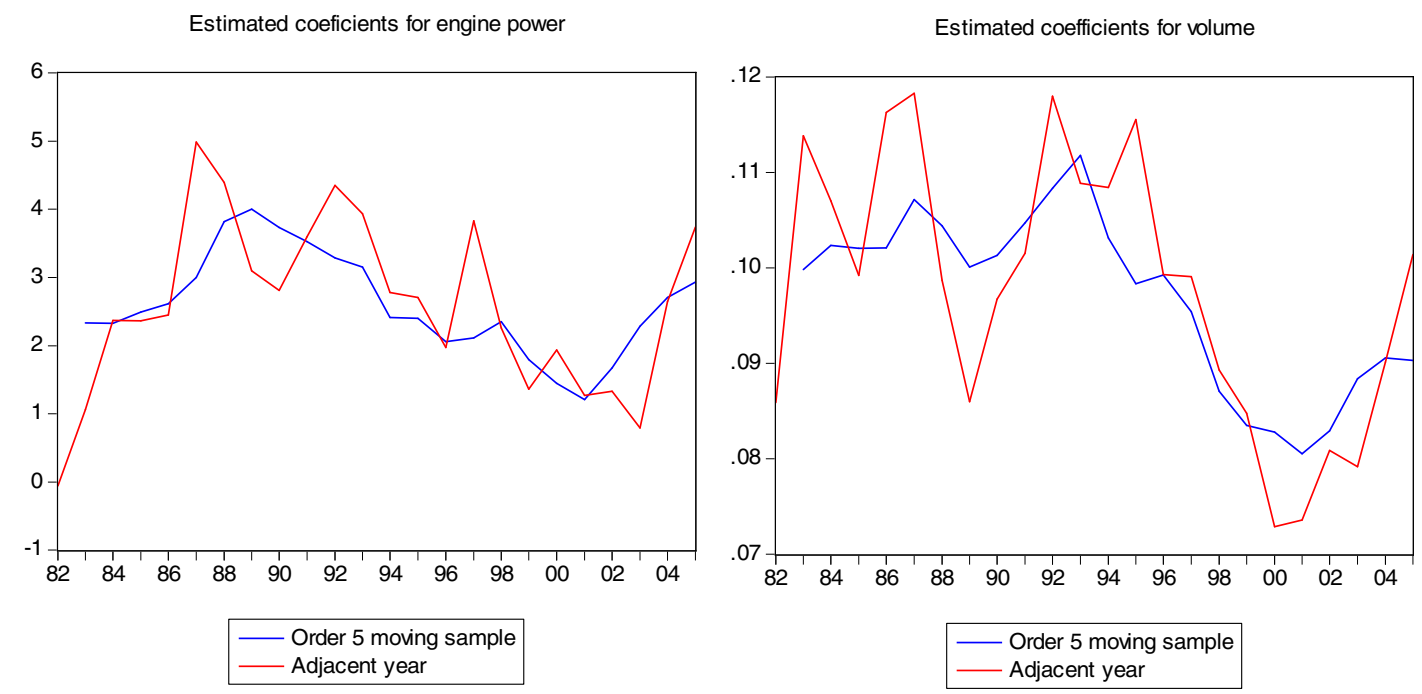

Figure 2. Normal density functions for the estimated elasticities
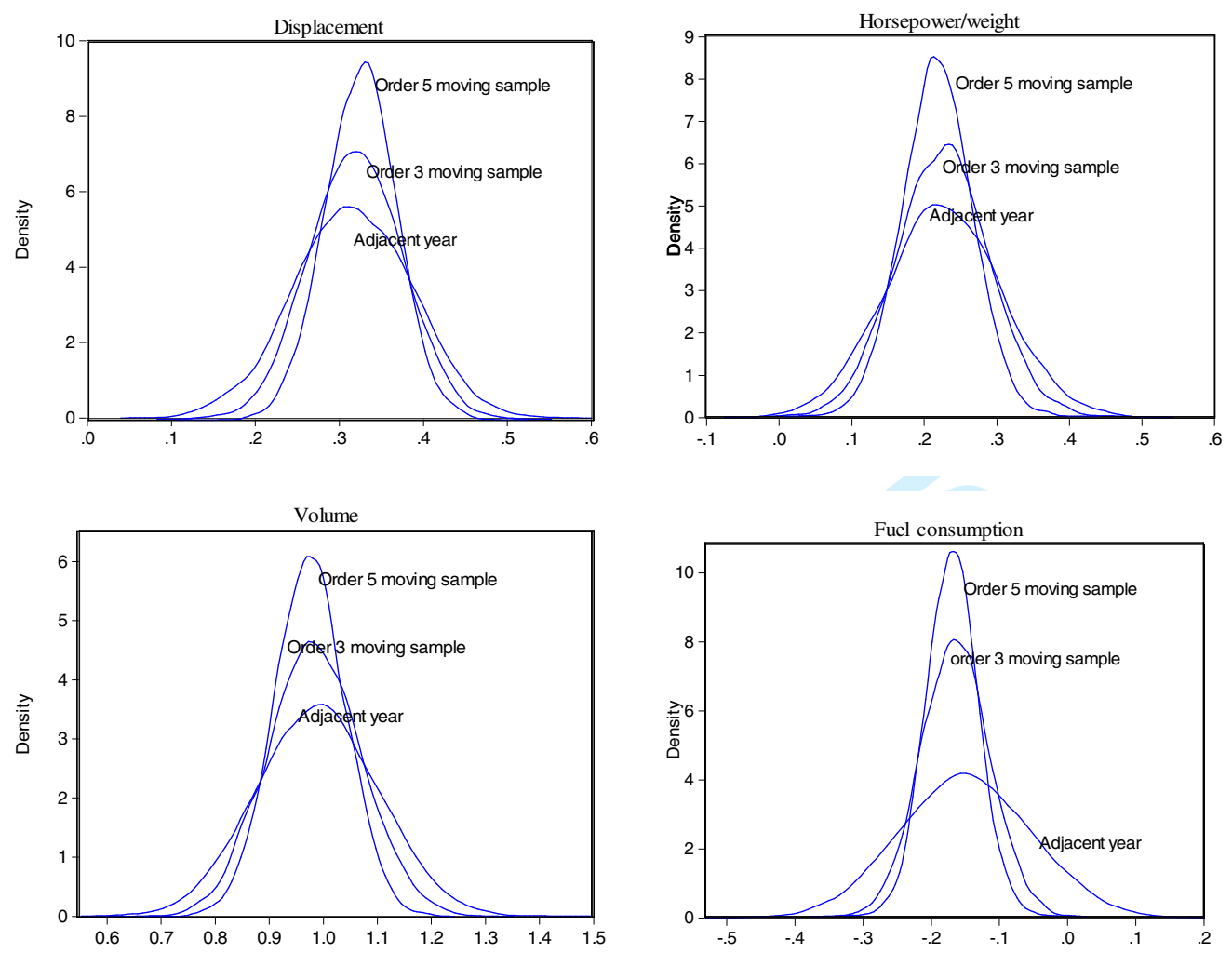
Figure 3. Rate of variation of the quality-adjusted price index

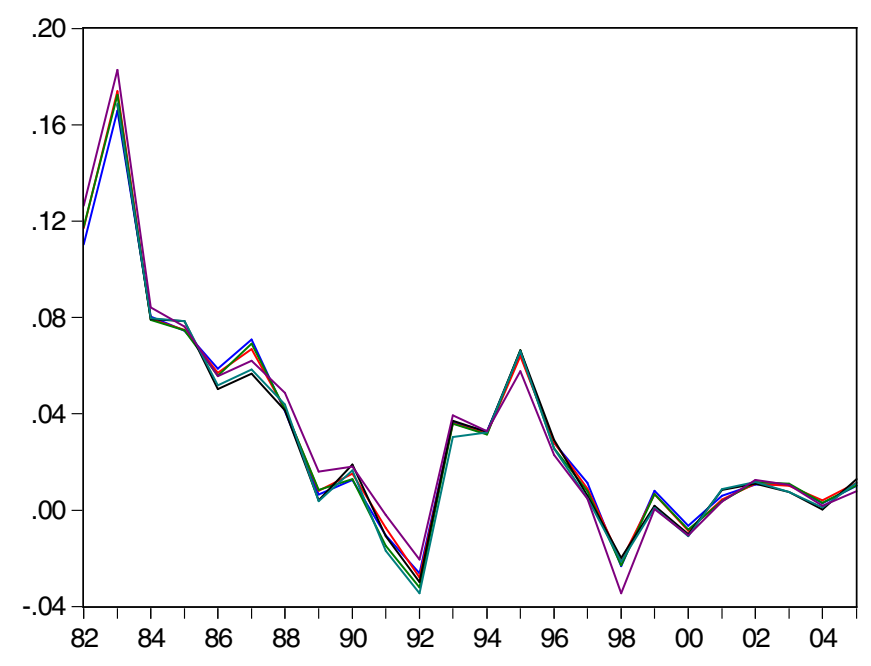

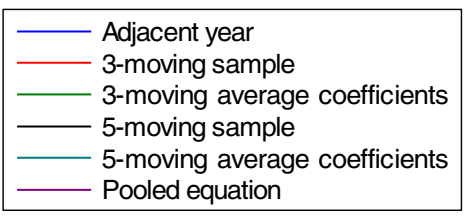


Figure 4. Quality indexes $(1981=1)$

Engine power

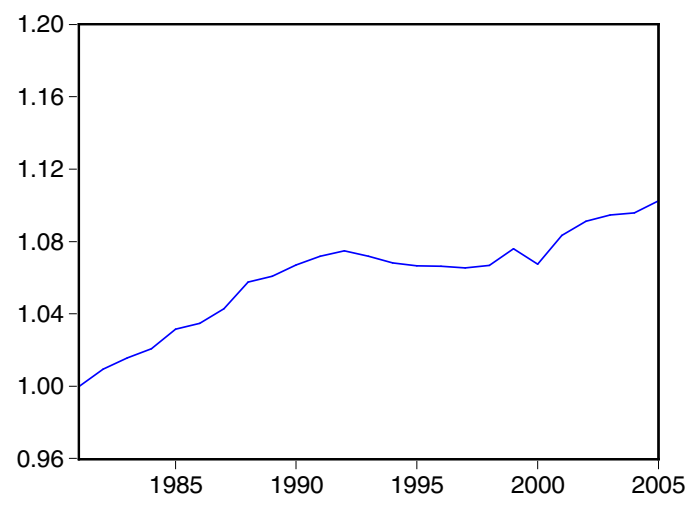

Size

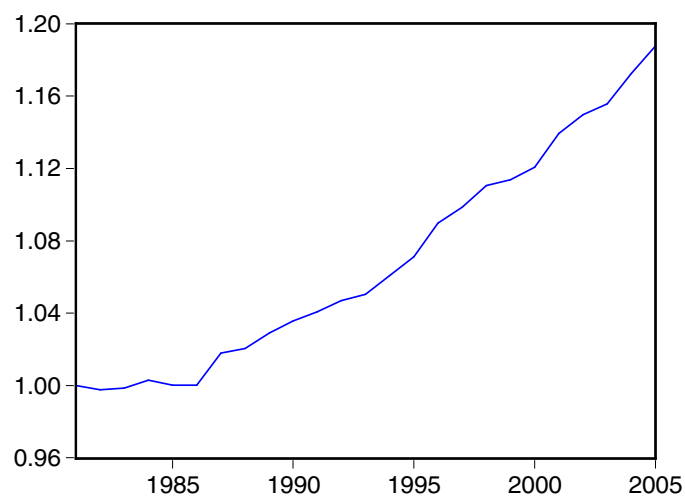

Fuel efficiency

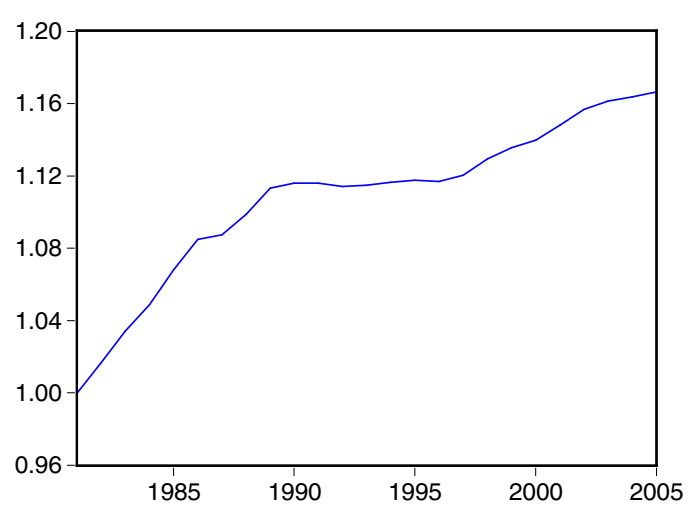

Ease of drive

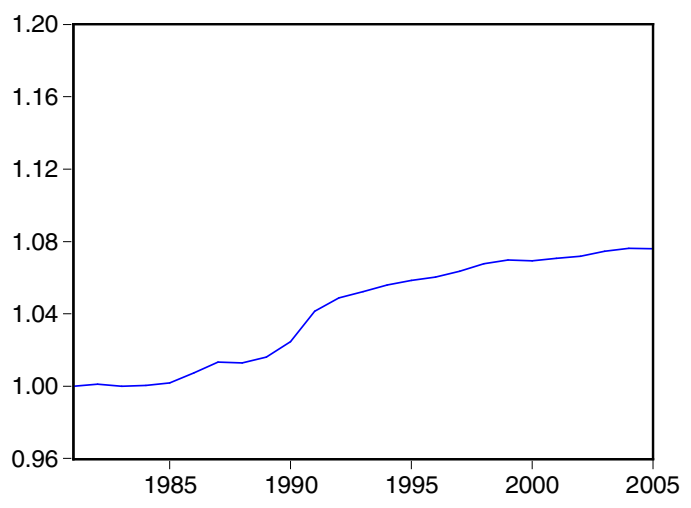

Comfort

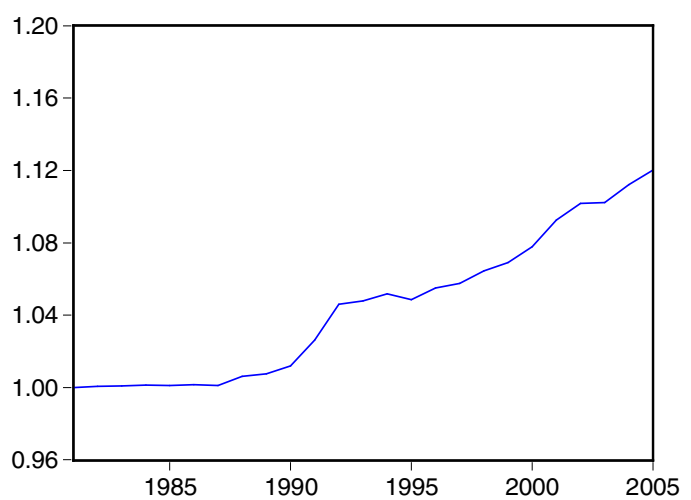

Safety

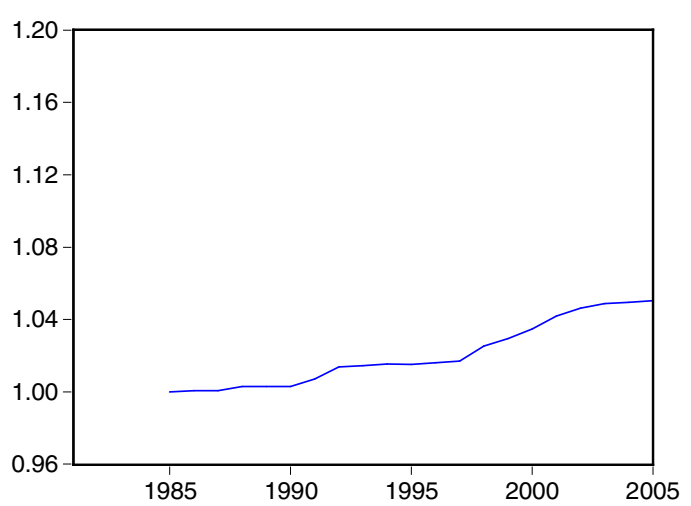


Figure 5. Sigma-convergence
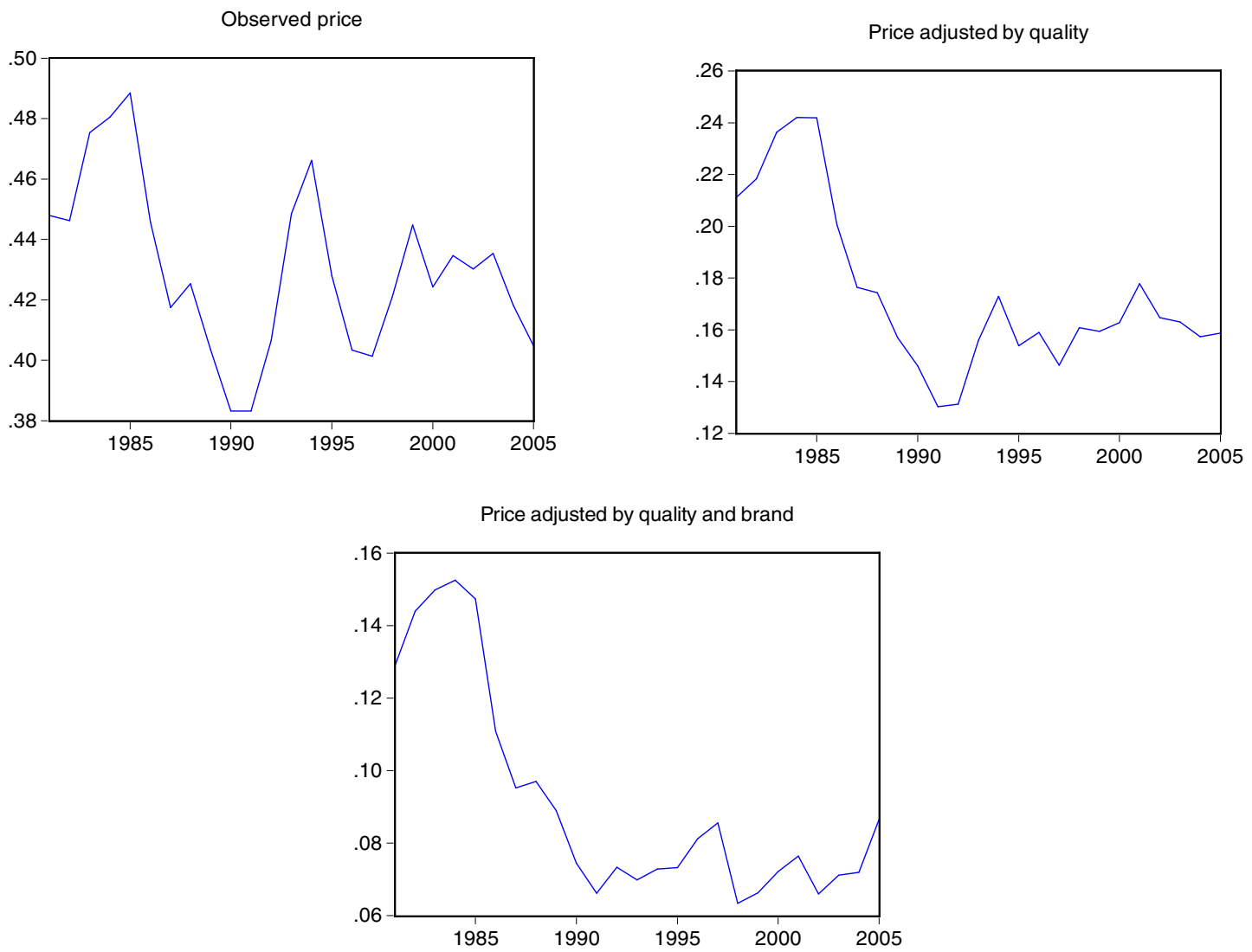

Figure 6. Price convergence and economic integration
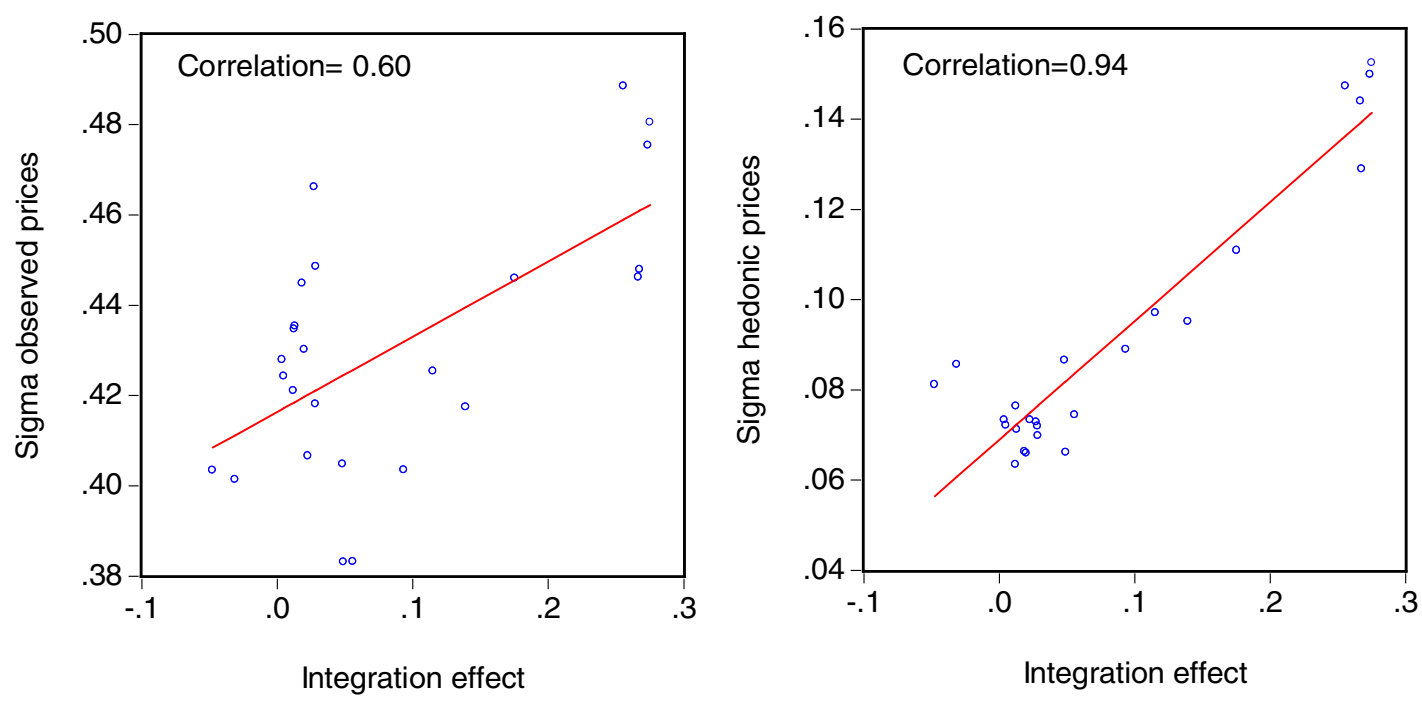